\title{
A Study of Quality Control Circle on the Reduction of the surgical Site Infection X Liu ${ }^{1}, \mathrm{~J} \mathrm{Wang}^{2}$
}

\begin{abstract}
Objective: The aim of this study was to discuss the value and significance of quality control circle (QCC) in the reduction of the surgical site infection (SSI).

Methods: From January 2012 to December 2013, a total of 32 patients with surgical site infection were included in the study. Quality control circle was established to control the SSI in these patients. The tangible and intangible results of QCC were compared and analysed.

Results: On the tangible results, achievement and improvement index on internal error reduction, SSI rate reduction, patients satisfaction, working quality improvement was $97.84 \% \pm 16.47 \%, 95.04 \% \pm 50.33 \%, 90.58 \% \pm 22.83 \%, 100.6 \% \pm 22.8 \%$ and $31.12 \% \pm$ $13.2 \%, 34.41 \% \pm 22.96 \%, 40.22 \% \pm 25.39 \%, 49.2 \% \pm 25.4 \%$. On the intangible results, one to two points improvement was found in $83 \%$ of the QCC members, and $12 \%$ of the QCC members have $>2$ points improvement.
\end{abstract}

Conclusion: Quality control circle could reduce the SSI rates, especially on the intangible and tangible results. Quality control circle could be employed as effective tool to improve the medical quality.

Keywords: Medical quality, operation, quality control circle, surgical site infection

From: ${ }^{1}$ Department of Operating-room, Weifang Peoples Hospital, Weifang City, Kuiwen District, 261041, China and ${ }^{2}$ Department of Operating-room, Maternity and Child Care Hospital, Weifang City, Weicheng District, 261011, China.

Correspondence: Dr J Wang, No. 76, Qingnian Road, Weicheng District, Weifang City, 261011, China, Shandong Province. Phone: +86-13869628756, E-mail: wjmhosp@163.com

West Indian Med J 2016;

DOI: 10.7727/wimj.2015.346 


\section{INTRODUCTION}

During the past 30 years, medical quality management system has been established in the hospitals in China. More attention has been paid on the consistent medical quality improvement and security management by the administration of Health department, and the good medical quality management concept has been established (1). Since 2001, quality control circle has been proposed by the Chinese medical agencies (2). The content of the quality control circle included reduction of the internal prescription error in the outpatients department, improvement on the quality of operative room nursing, decreasing the complications caused by the venous indwelling needle, and increasing the inspection rate of the urine and feces in orthopedic patients (3). All these achievements are related with nursing technology and management. Here, we presented a study about the value and significance of quality control circle (QCC) in the reduction of the surgical site infection (SSI).

\section{MATERIALS AND METHODS}

\section{Project selection}

This study will focus on the relationship between the of medical staff and SSI, evaluate the association between operation room staff and SSI risk change by using infection risk assessment and observe the consciousness of the operation room staff in emergency condition. 


\section{Establishment of the QCC group}

In order to condense the QCC confidence, make sure the implementation of the QCC, fulfill the goal of the QQC, all the member gathered to form a circle, and make a vow to improve the determination and will. An efficient QCC was initiated from finding suitable member. The best QCC group included 5-10 persons, and formed via voluntary registration. Our QCC group was formed by seven nurses, of them, two were co-chief nurses, four were nurse in charge and two were nurse practitioner. Three of them are member of infection prevention team of our hospital. The head nurse took the counsellor position, and one of the nurses in charge was selected as the leader of QCC group. All the members were from the same division or workplace. Each member has their own working responsibility.

\section{Patients}

From the January 2012 to December 2013, 309 patients were performed with surgery in our hospital. Of them, 32 were SSI patients. The mean age of the patients were 67 years (range 60-75 years), 20 were males and 12 were females. Of the SSI patients, 14 patients were presented with lung cancer SSI, seven were burn SSI, three were trauma SSI, six were circumcision or perirectal SSI, two were cesarean section SSI. The other clinical manifestation was comparable between patients. All the patient demographic data was shown in Table 1. The written informed consents from the patients were confirmed and approved by the local institutional ethics committee. 
Table 1. Patient demography $\mathrm{n}=92$

\begin{tabular}{|c|c|c|c|}
\hline Parameter & $\begin{array}{l}\text { Total Number } \\
(\mathrm{N})\end{array}$ & $\begin{array}{l}\text { Surgical } \\
\text { site infection } \\
(n, \%)\end{array}$ & $p$-valule \\
\hline Age (yrs) & & & 0.995 \\
\hline$<65$ & 55 & 60 & \\
\hline $65-74$ & 25 & 27 & \\
\hline$\geq 75$ & 12 & 13 & \\
\hline Gender & & & 0.209 \\
\hline Male & 51 & 55 & \\
\hline Female & 41 & 45 & \\
\hline $\begin{array}{l}\text { Body mass index (BMI, } \\
\left.\mathrm{Kg} / \mathrm{m}^{2}\right)\end{array}$ & & & 0.381 \\
\hline$<25$ & 56 & 61 & \\
\hline$\geq 25$ & 36 & 39 & \\
\hline Preoperative albumin (g/dL) & & & 0.846 \\
\hline$<3.5$ & 43 & 47 & \\
\hline$\geq 3.5$ & 49 & 53 & \\
\hline $\begin{array}{l}\text { Preoperative haemoglobin } \\
(\mathrm{g} / \mathrm{dL})\end{array}$ & & & 0.422 \\
\hline$<10$ & 50 & 54 & \\
\hline$\geq 10$ & 42 & 46 & \\
\hline
\end{tabular}

\section{The protocol of QCC}

Quality control circle training content: objective, procedure and method. All the training was carried out by the QCC activity trainer. The key point was to strengthen the ideology, encourage the member to establish the attitude about "I wish to do, I'd like to do, and I could do". All the training was performed via class training and personal training combination. At the beginning of the QCC activity, the member and the leader were asked to deal with the practical problem via brain storm and making use of the on site data and material. All the QCC ideas were analysed and revised according to the quality management. Quality control circle meetings were held regularly. There are 10 steps in the activity of QCC: topic selection, 
activity design, situation understanding, making goals, analysis, strategy making, process and assessment, result confirm, standardization, review and improvement.

\section{Data collection}

According to the characteristic of QCC, we summarized the data as follows: internal error reduction, SSI infection rate reduction, patients satisfaction improvement, working quality improvement. Achievement index $=[($ Preimprovement value- postimprovement value $) /$ (target value-preimprovement value $)] \times 100 \%$; Improvement index $=[($ Preimprovement value-postimprovement value) / preimprovement value] $\times 100 \%$.

\section{Statistical analysis}

All the statistical analysis was performed by using SPSS 19.0 software. Counting data were presented as percentages. The difference between groups was tested by $\chi^{2}$ and the results were presented as Mean \pm Standard deviation $(\mathrm{SD}), p<0.05$ was considered as statistical significance.

\section{RESULTS}

\section{Tangible results}

Based on the QCC topic activity, the tangible results included internal error reduction, SSI infection rate reduction, patients' satisfaction improvement, working quality improvement. As shown in Table 2, the achievement index on internal error reduction, SSI infection rate 
reduction, patients satisfaction improvement, working quality improvement were $97.84 \% \pm$ $16.47 \%, 95.04 \% \pm 50.33 \%, 90.58 \% \pm 22.83 \%, 100.6 \% \pm 22.8 \%$, respectively and improvement index on internal error reduction, SSI rate reduction, patients satisfaction, working quality improvement were $31.12 \% \pm 13.2 \%, 34.41 \% \pm 22.96 \%, 40.22 \% \pm 25.39 \%$, $49.2 \% \pm 25.4 \%$, respectively.

Table 2. The results of achievement and improvement after quality control circle activity (\%, Mean \pm SD)

\begin{tabular}{llcll}
\hline $\begin{array}{l}\text { Activity } \\
\text { index }\end{array}$ & $\begin{array}{l}\text { Internal error } \\
\text { reduction }\end{array}$ & $\begin{array}{c}\text { Operation room } \\
\text { infection rate } \\
\text { reduction }\end{array}$ & $\begin{array}{l}\text { Patients } \\
\text { satisfaction }\end{array}$ & $\begin{array}{c}\text { Working quality } \\
\text { improvement }\end{array}$ \\
$\begin{array}{l}\text { Achievement } \\
\text { index }\end{array}$ & $97.84 \% \pm 16.47 \%$ & $95.04 \% \pm 50.33 \%$ & $90.58 \% \pm 22.83 \%$ & $100.6 \% \pm 22.8 \%$ \\
$\begin{array}{l}\text { Improvement } \\
\text { index }\end{array}$ & $31.12 \% \pm 13.2 \%$ & $34.41 \% \pm 22.96 \%$ & $40.22 \% \pm 25.39 \%$ & $49.2 \% \pm 25.4 \%$ \\
& & & &
\end{tabular}

\section{Intangible results}

The intangible results included problem-solving, responsibility, communication and coordination, confidence, cohesiveness, subjective initiative, harmony, honor, individual quantification. The assessment was performed by using self-evaluation questionnaire, five were highest, one is lowest. All the members were presented with improvement. Among them, $83 \%$ showed an ability improvement for $1-2$ points, $12 \%$ were showed ability improvement for $>2$ points. The data were shown in Table 3 . 
Table 3. The improvement of intangible index

\begin{tabular}{lllll}
\hline Intangible index & $\begin{array}{l}\text { Internal error } \\
\text { reduction }\end{array}$ & $\begin{array}{l}\text { Operation } \\
\text { room } \\
\text { infection } \\
\text { reduction }\end{array}$ & $\begin{array}{l}\text { Patients } \\
\text { satisfaction }\end{array}$ & $\begin{array}{l}\text { Working } \\
\text { quality } \\
\text { improvement }\end{array}$ \\
Problem-solving & $1.4 \pm 0.6$ & $0.9 \pm 0.1$ & $1.3 \pm 0.6$ & $1.5 \pm 0.7$ \\
Responsibility & $1.3 \pm 0.8$ & $0.9 \pm 0.5$ & $1.4 \pm 0.8$ & $1.2 \pm 0.7$ \\
Communication & $1.2 \pm 0.5$ & $1.4 \pm 0.5$ & $1.4 \pm 0.7$ & $1.3 \pm 0.9$ \\
and coordination & $1.5 \pm 0.6$ & $1.3 \pm 0.6$ & $1.3 \pm 0.8$ & $1.1 \pm 0.8$ \\
Confidence & $1.3 \pm 0.6$ & $1.1 \pm 0.8$ & $1.5 \pm 0.7$ & $1.3 \pm 0.7$ \\
Cohesiveness & $1.3 \pm 0.7$ & $1.1 \pm 0.9$ & $1.5 \pm 0.6$ & $1.5 \pm 0.8$ \\
Subjective initiative & $1.3 \pm 0.7$ & $1.4 \pm 0.4$ & $2.6 \pm 0.9$ & $1.5 \pm 0.8$ \\
Harmony & $1.2 \pm 0.5$ & $1.2 \pm 0.5$ & $1.1 \pm 0.7$ & $1.3 \pm 0.7$ \\
Honour & $1.4 \pm 0.8$ & $1.2 \pm 0.3$ & - & $1.3 \pm 0.5$ \\
\hline Individual qualification & 1.4 & & \\
\hline
\end{tabular}

\section{DISCUSSION}

The content and objective of modern QCC has passed its limitation of modern enterprise management (4). The QCC has been gradually applied into the area of health. The objective of QCC was to improve the ability of medical staff, solve the medical problem, improve the medical working environment, and ultimately improve the morale of the medical staff, medical quality, decreasing the cost of the medical management, and improve the efficacy of medical service. Operation room is specific place in the hospital, and most of SSI risk were from the operation room $(4,5)$. According to previous studies, several processes such as skin degerming, antibiotic, environment controlling, improvement of the operative technology were involved in the decreasing of the SSI infection risk to improve the patient safety and medical quality (6). However, the reports about the microbe infection at the surgical site are 
rare. The relationship between the behaviour of medical staff and SSI risk has been discussed in previous studies $(7,8)$. According the MEDLINE searching results, we found eight paper about assessment of the association between QCC and operation room infection (9), and the results vary among the different studies. Moreover, we found five paper about assessment of the number of door opening, number of participants during the surgery (10). Of them, four were description study and one concluded that there was association between number of participants and SSI risk (11). All these studies were based on the manual observation in the given time. The observed results might cause two bias, Hawthorne effect and dynamic change of the local observation. The other two papers were about the behaviour performance on the results of the SSI (12). The last paper is about the influence of the noise and the author found that positive association between Decibel increasing and SSI rate. However, lacking of systemic and consistent evaluation of the medical staff in operation room were found in all these studies $(13,14)$.

We here designed a QCC based activity for the prevention of the operation room complications. The results included tangible and intangible results. The tangible results included data about internal error reduction, infection rate in operation room reduction, patients satisfaction improvement, working quality improvement (15). The achievement index on internal error reduction, SSI infection rate reduction, patients satisfaction improvement, working quality improvement were $97.84 \% \pm 16.47 \%, 95.04 \% \pm 50.33 \%$, $90.58 \% \pm 22.83 \%, 100.6 \% \pm 22.8 \%$, respectively and improvement index on internal error reduction, SSI rate reduction, patients satisfaction, working quality improvement were $31.12 \% \pm 13.2 \%, 34.41 \% \pm 22.96 \%, 40.22 \% \pm 25.39 \%, 49.2 \% \pm 25.4 \%$, respectively. 
Intangible results included problem-solving, responsibility, communication and coordination, confidence, cohesiveness, subjective initiative, harmony, honor, individual quantification. The assessment was performed by using self evaluation questionnaire, five were highest, one is lowest. All the members were presented with improvement. Among them, 83\% showed a ability improvement for 1-2 points, $12 \%$ were showed ability improvement for $>2$ points. The quantifiable outcomes included defect rate, error rate, delay rate, number of patient complaints and absence rate. The tangible results were more attractive than the intangible.

If the achievement index is $>150 \%$, a low confident level will be presented when setting the objective. If the achievement is $<80 \%$, an overestimation will be presented on the improvement of the QCC. Intangible results such as growth of the group leader and the counsellor are hard to quantify (16-18). Quality control circle could promote the working morale, improve the knowledge and technology of the medical staff, encourage the working attitude, cultivate the leadership, improve the image of medical agency, decreased the cost of system, increase the patients satisfaction $(19,20)$.

In conclusion, QCC could decrease the SSI complication risk and improve the intangible and tangible results. Quality control circle could be used as effective tool to improve the medical quality. 


\section{REFERENCES}

1. Wang $\mathrm{X}$ : The impact of quality control circle on the satisfactory rate of nursing activity. Chin Gen Nurs 2011, 9: 1089-1090.

2. Shao C, Jin Y, Zhu S: The effect of quality control circle in the nursing management. Nurs Rehabil J 2012, 11: 381-82.

3. Xu C, Ke Y, Chen R, Feng F, Cai Q: The application of quality control circle activity in pathlogical specimen management. Chin Nurs Manag 2012; 12: 20-23.

4. Fang D, Zhang H, Jiang Q, Xu H: Effect of quality control circle on improving the compliance of bedhead elevation in prevention of ventilator-associated pneumonia. Chin J Nosocomiol 2013; 23: 773-74.

5. $\mathrm{Hu} \mathrm{Z}$, Wan $\mathrm{C}, \mathrm{Xu} \mathrm{L}$ : The application of quality control circle on improvement of healthy statue of RA patients. Pract Clin Med 2014, 15: 91-93.

6. Liang M, Liu T, Dong S: Research on the Application of Quality Control Circle in Continuous Improvement of Medical Quality. Chin Hosp Manag 2012, 32: 37-39.

7. Pang H, Pan B: Application of quality control circle activities in management of hand disinfection of medical staff in ICU. Chin J Nosocomiol 2012, 22: 2154-55.

8. Zhang F, Yu Y, Xu Z, Huang J, Dai Z, Huang Y et al. Effect of quality control circle program in the quality management of basic nursing in psychiatric wards for the elderly. Chin J Nurs 2013, 48: 127-130.

9. Lynch RJ, Englesbe MJ, Sturm L, Bitar A, Budhiraj K, Kolla S et al. Measurement of foot traffic in the operating room: implications for infection control. Am J Med Qual 2009; 24: 45-52. 
10. Cai X, Wang P, Xu J, Yao Q: Shortening waiting time for an endoscopic procedure through quality control circle. J Nurs Sci 2013, 28: 1-4.

11. $\mathrm{BH} \mathrm{M}, \mathrm{ZM} \mathrm{Z}, \mathrm{MH} \mathrm{L}$ : The application of quality control circle in the quality management of nursing. Chin J Hosp Admin 2012; 28: 286-88.

12. Shi L, Xu H, Zhou D, Jin Y, Li L: Reducing urinary tract infections in patients performing intermittent self-catheterization at home by quality circle. J Nurs Sci 2013: 18-19.

13. DM S, YX W: The preliminary exploration of quality control circle in demonstration ward. Chin Forgn Med Res. 2012; 10: 99-100.

14. Wang Y, Qin X, Gao X, Fan J, Wang G, Li F et al. The application of quality control circle in the consistent quality management of nursing. Chin J Hosp Admin 2014, 30: $425-27$.

15. Pan H, Yan B: Application of quality control circle activities in management of hand disinfection of medical staff in ICU. Chin J Nosocomiol 2012, 22: 2154-55.

16. Li Q, Wang F, Gao J, Shu C, Zhang H, Luo Y et al. The impact of quality control circle on the acknowledgement and behavior of the nurse. Chin Pharm 2013, 24: 4390-92.

17. Shen L, Feng S, Zhu X, Fan J: Observation of quality control circle on the compliance improvement of medical staff. Nurs Rehabil J 2011, 10: 907-09.

18. Zhang L, Dai X, Yang N: The application of Application of quality control circle activities in continuous quality improvement in stoma patients. J Nurs Sci 2013, 28: $71-72$ 
19. Liang L, Huang H, Xu B, Zhang J, Li Y, Liao G: The effect of quality control circle on thereducing of the mistake events in the pharmacy. Chin Pharm. 2012, 23: $2350-52$.

20. QLTan, Gu B, Hu Y: Application of quality control circle in nurses emotional control and anagement. Chin Nurs Res 2013, 26: 3235-36. 